تخمين زيستفراهمى منابع مختلف عنصر روى رهاء

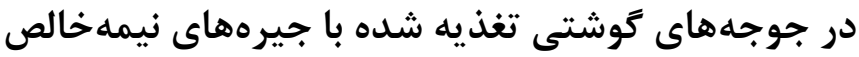

\author{
محمود صحرايى' و حسين جانمحمدى' \\ 1- بخش تحقيقات علوم دامى، مركز تحقيقات و آموزش كشاورزى و منابع طبيعى استان اردبيل (مغان)، سازمان تحقيقات، آموزش و

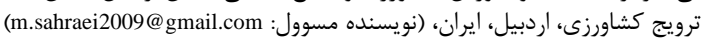

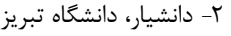

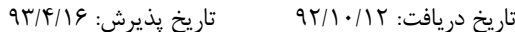

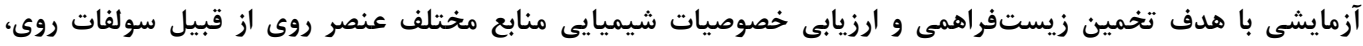

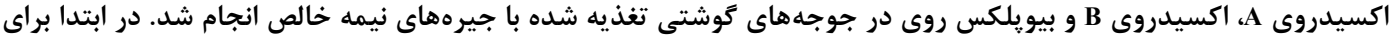

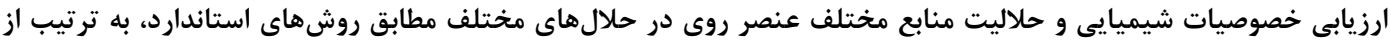

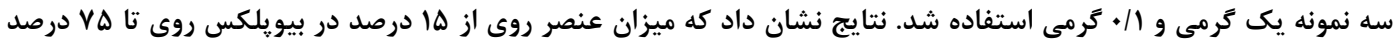

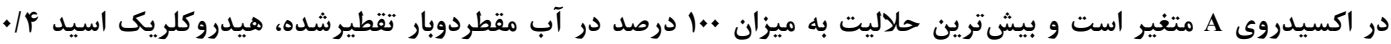

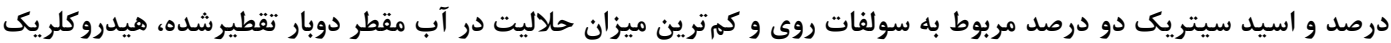

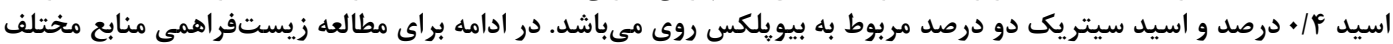

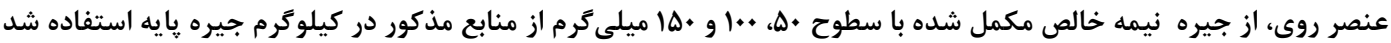

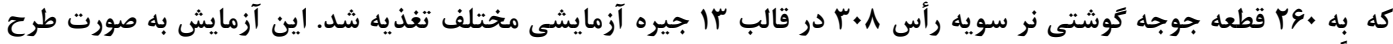

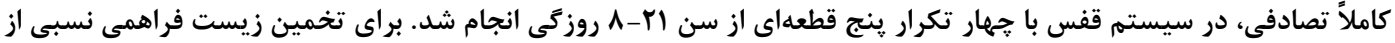

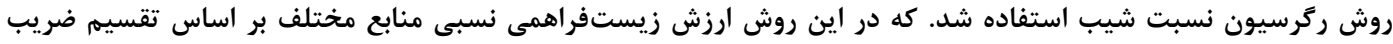

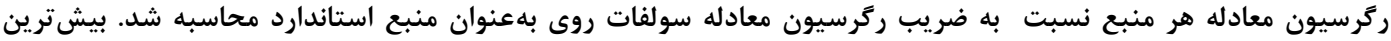

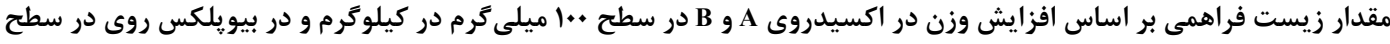

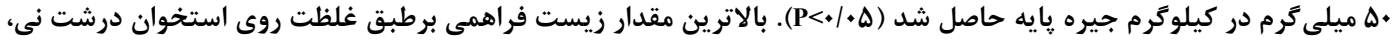

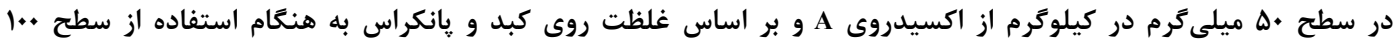
ميلى

وازههاى كليدى: زيستفراهمى، حلاليت، جيره نيمه خالص، روى، جوجه كوشتى

اكسيدروى و سولفات روى تك نك آبه را ززارش كردند.

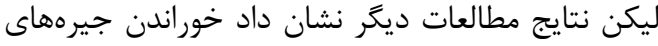

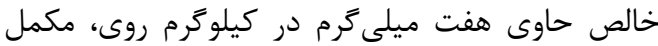

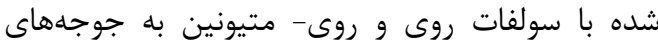

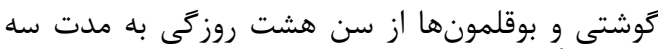

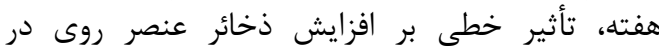

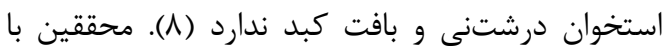

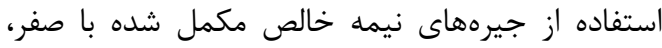

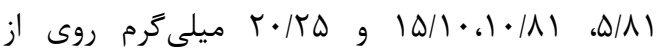

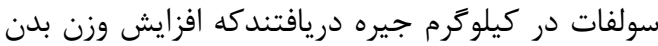

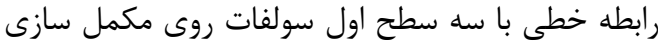

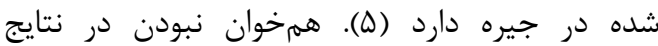

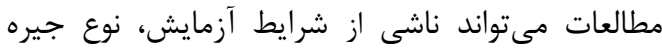

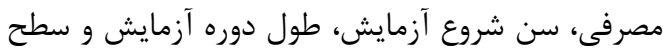

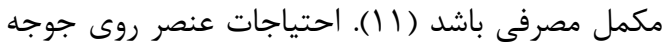

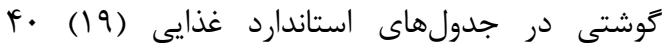
ميلى
مقدمه

عنصر روى بلهرغم اينكه متعلق به عناصر كم نياز

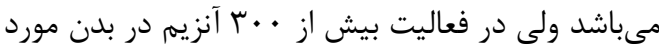

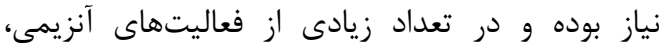

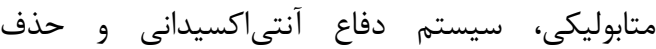

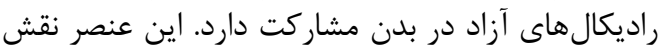

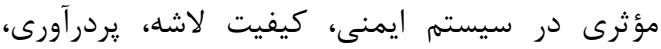

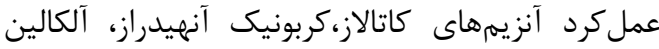

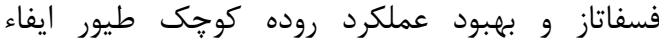

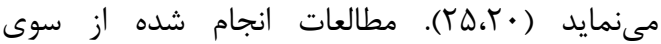

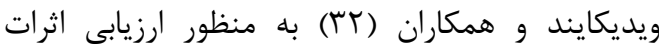

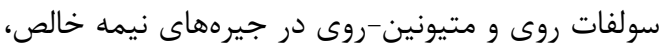

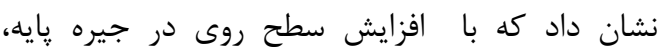

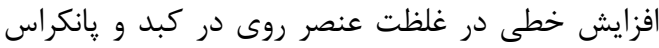

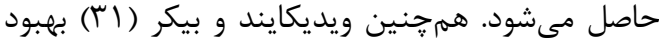

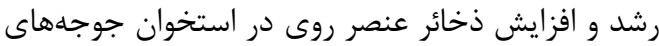

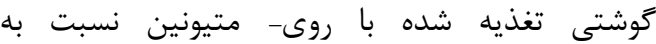




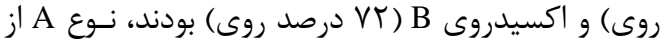

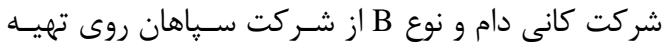

شد.

1- ت تعيين تركيبات شيميايى

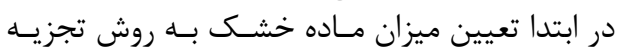

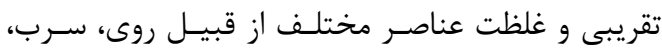

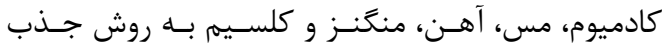

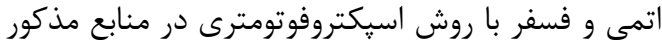

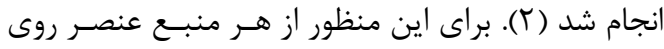

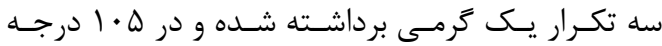

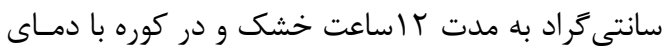

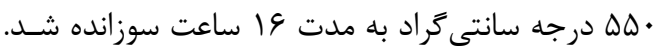

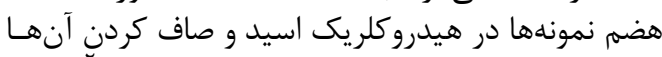

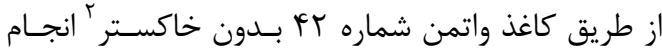

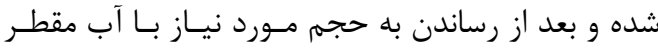

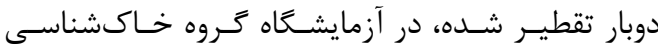

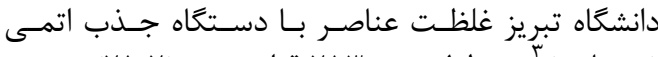

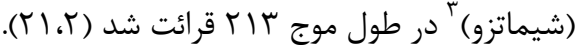

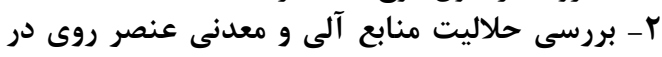

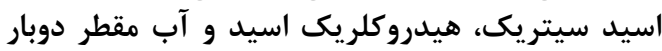
تقطيرشده

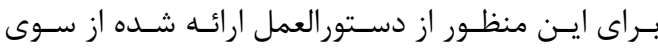

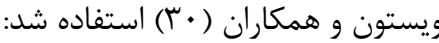

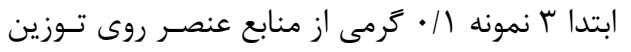

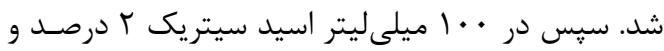

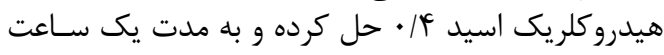

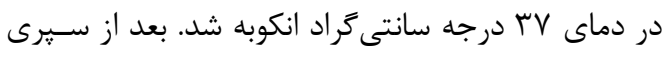

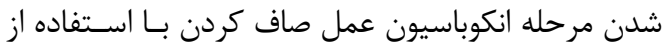

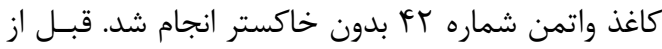

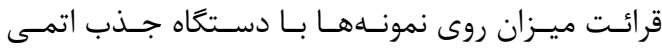

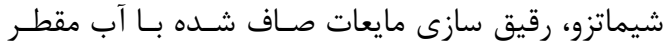

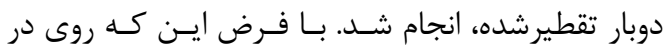

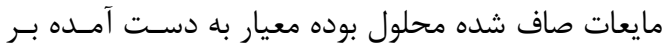

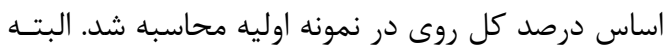

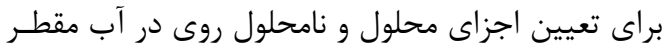

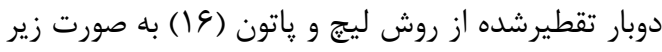

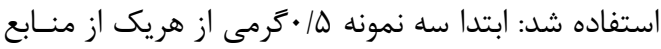

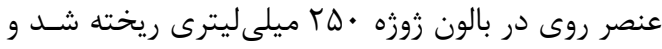

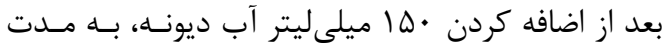

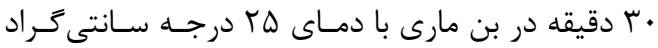

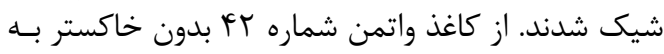

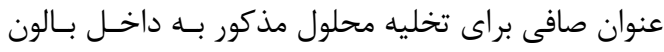

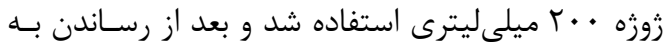

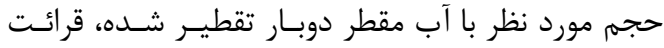

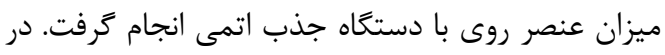

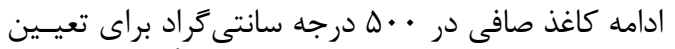

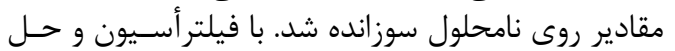

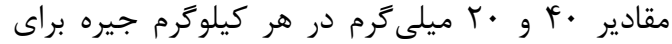

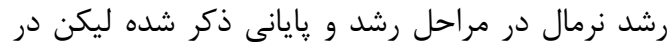

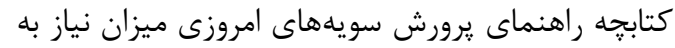

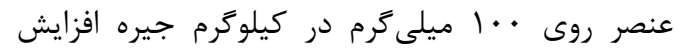

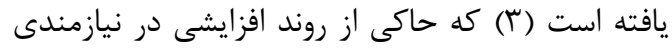

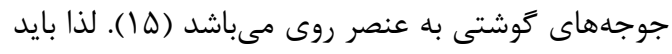

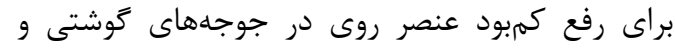

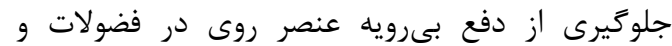

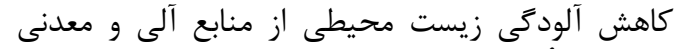

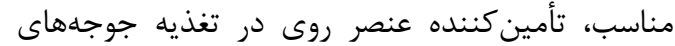

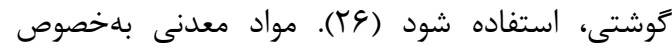

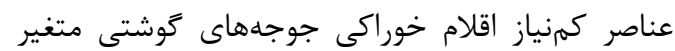

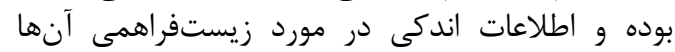
وجود دارد و بر اساس دادهات انهاى محدود ميزان زيت زيست فراهمى آنها نيز متفاوت است (أع).

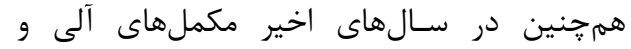

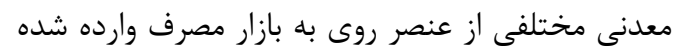

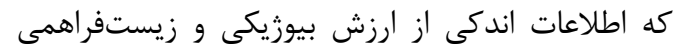

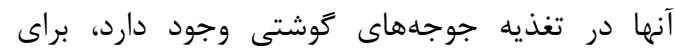

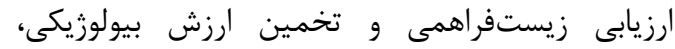

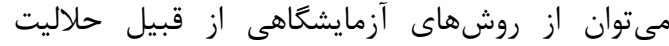

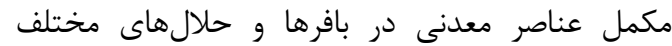

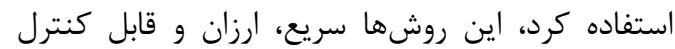

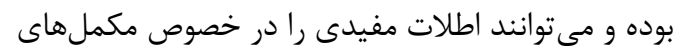

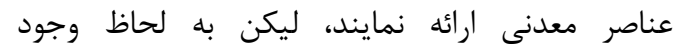

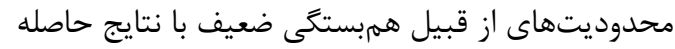

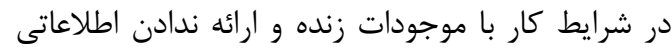

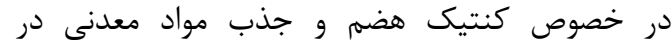

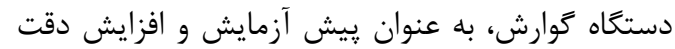

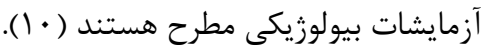

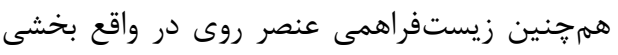

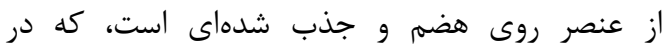
متابوليسم حيوان قابل استفاده باشد لذاب لذا انتخاب معيار

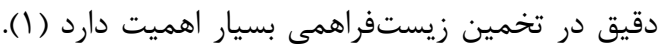

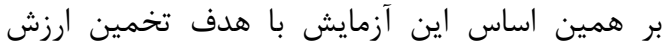

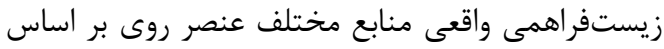

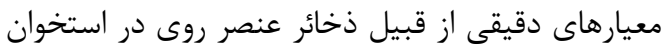

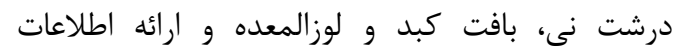
تكميلى در جوجههاى كَشتى انجام شد. تعيين تركيبات شيميايى و حلاليت منابع آلى و معدنى عنصر روى

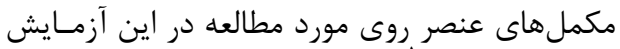

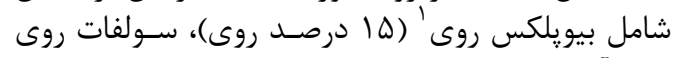

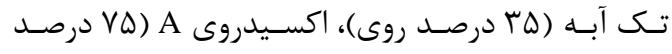


آزمايش از نور مستمر بF ساعته در سالن اسـتفاده شـد.

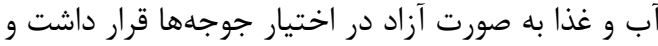

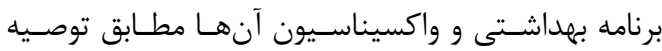

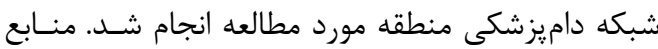

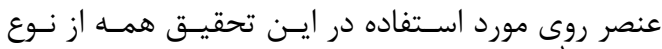

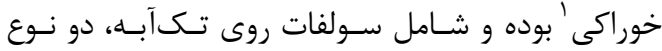

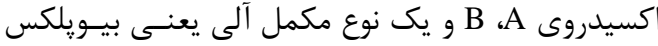

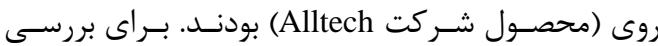

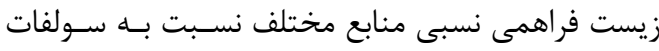

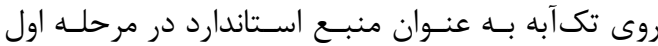

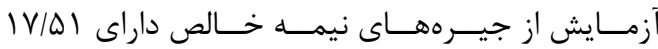

ميلى گرم در كيلوگرم روى استفاده شد (جدول () ).
كردن خاكستر كاغذ صافى حاوى مواد نـامحلول در يــنج

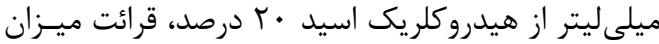

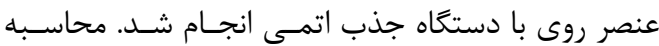

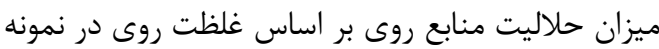

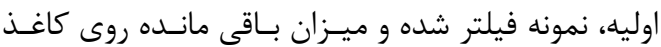

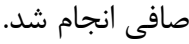

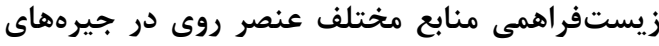

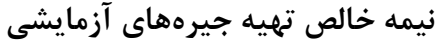

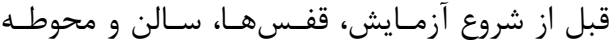

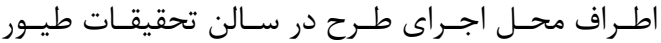

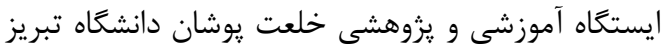

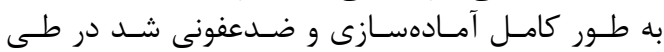

\begin{tabular}{|c|c|c|c|}
\hline مقدار & تركيبات مواد مغذى **** & 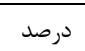 & مواد خوراكى \\
\hline 19 & ماده خشك (./) & $\Delta r / \varphi$ & نشاسته ذرت \\
\hline$r \ldots$ & انرزى قابل متابوليسم (كيلوكالرى/ كيلوكرم) & rq/1k & سوياى خوراكى ( (له درصد يروتئين خام) \\
\hline$r \cdot 1 / 9$ & 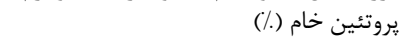 & $r$ & 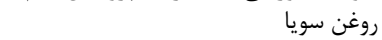 \\
\hline.$/ 94$ & كلسيم (./) & $r / r$ & كنجاله كلوتن (•4 درصد يروتئين خام) \\
\hline . & فسفر قابل دسترس (.) & $1 / V$ & 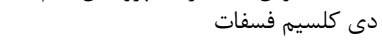 \\
\hline $1 / 11$ & لايزين (./) & $1 / 4$ & كربنات كلسيم \\
\hline . & متيونين (./) & $\cdot / \pi$ & نمكى \\
\hline.$/ 91$ & متيونين + سيستين (.) & r & دى ال- متيونين \\
\hline$\Delta F$ & آهن (ميلى گرم/ كيلوكرم) &.$/ 14$ & ال- لايزين هيدروكلرايد \\
\hline r) & مس (ميلى كرم/ كيلوكرم) & $\cdot / T \Delta$ & مكمل ويتامين" \\
\hline$\Delta V$ & منَنزز (ميلى كرم/ كيلوكَرم) & $\cdot / r \Delta$ & مكمل معدنى بدون روى هـ \\
\hline$|V / \Delta|$ & روى (ميلى گرم/ كيلو گرم) & $1 \cdots$ & جمع \\
\hline \multicolumn{4}{|c|}{ 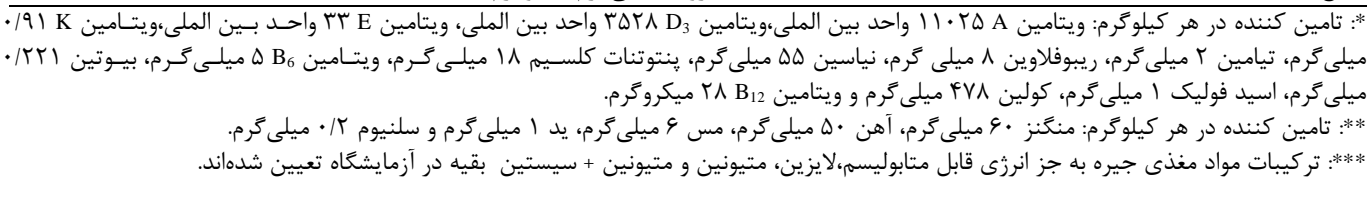 } \\
\hline
\end{tabular}

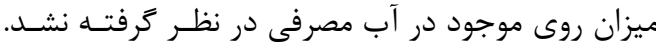

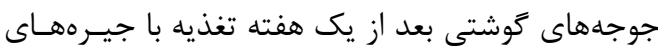

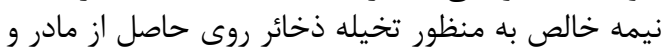

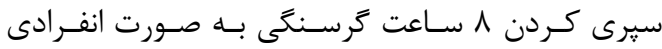

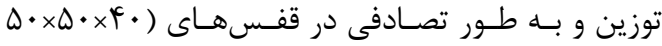

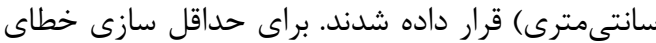

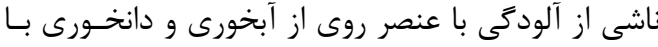

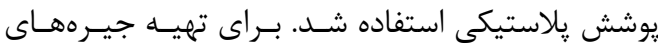

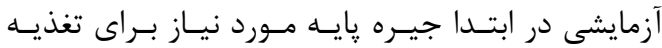

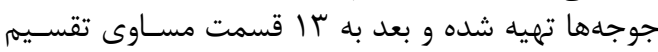

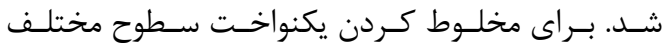

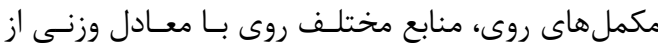

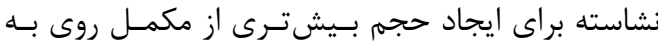

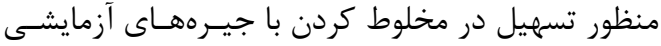

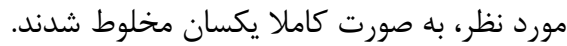

در اين آزمايش از يـك نــوع مكمـل آلـى بيـويلكس

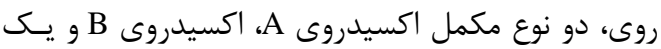

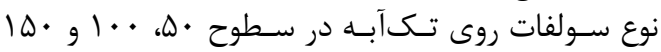

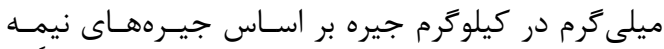

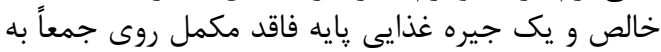

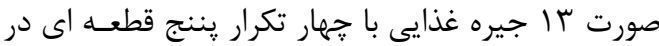

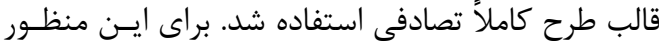

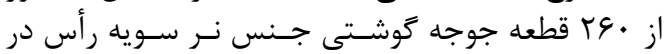

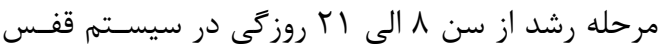

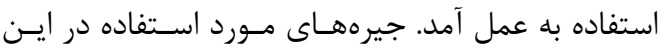

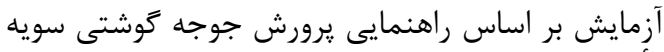

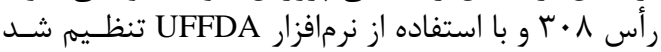

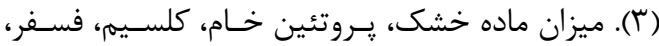

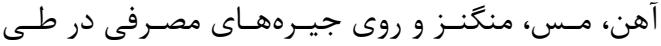

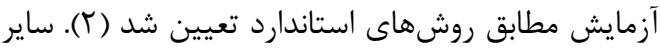

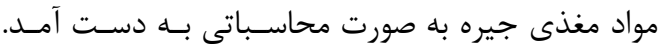




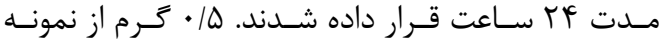

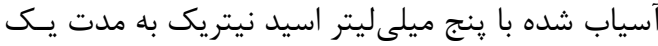

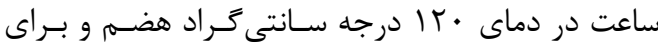

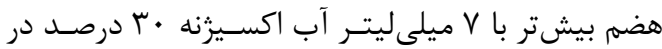

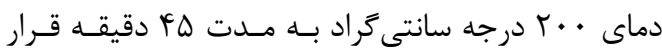

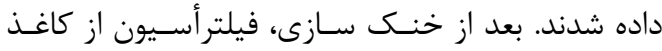

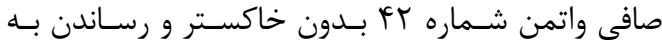

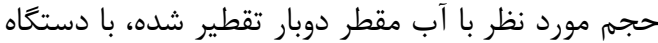

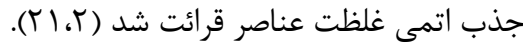

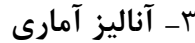

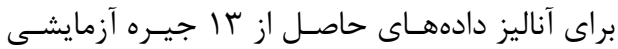

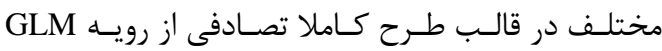
برنامه SAS9.1 بر اساس مدل آمارى زير استفاده شد: $Y_{i j}=\mu+T_{i}+e_{i j}$

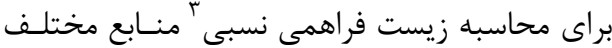

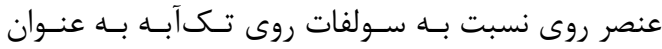

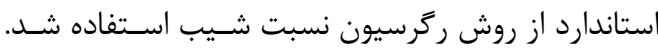

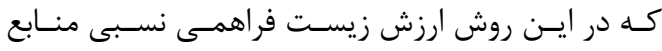

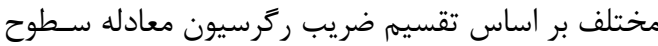

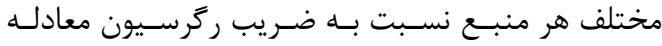

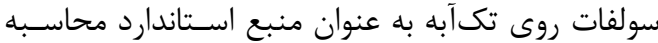

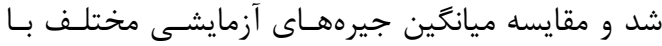

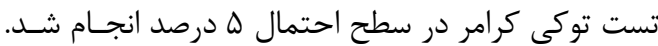

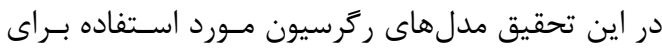

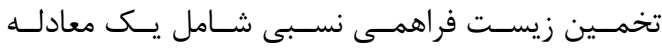
رخرسيون استاندارد (Y=a+bs فرضى براى ماده مورد آزمايش (Y=a+bt

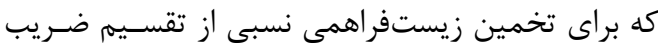

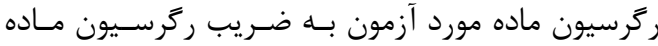

استاندارد استفاده شد (1) (1).

\section{ارزيابى خصوصيات شيميايسى و حلاليـت منــابع آلـى و \\ معدنى عنصر روى حصوي}

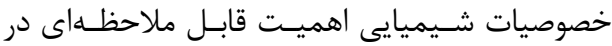

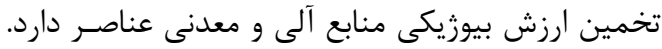

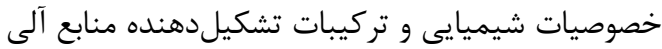

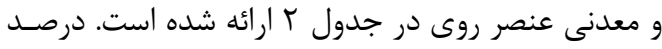

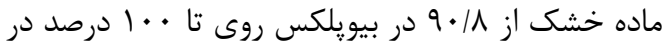

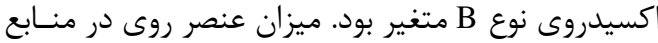

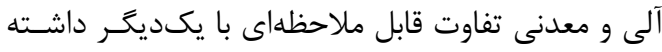

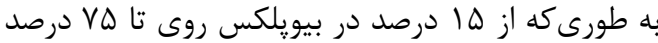

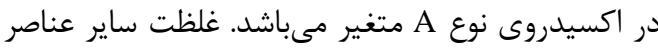

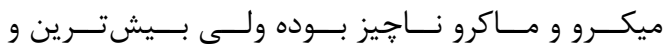

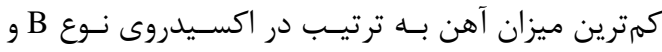

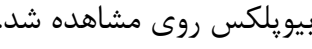

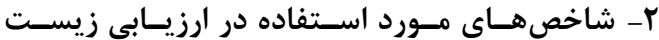
فر اهمى، جمع آورى و آناليز نمونهها

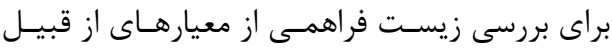

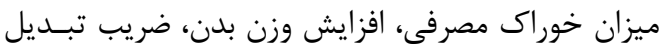

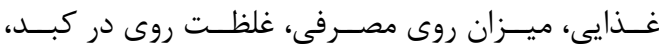

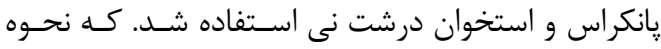
انجام هر كدام به شرح زير ارائه مي شئ شود:

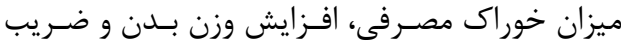

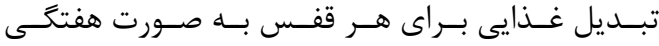

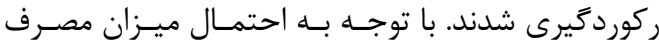

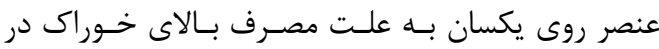

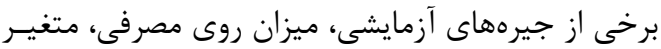

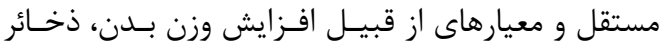

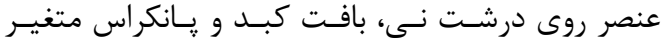

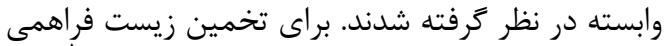

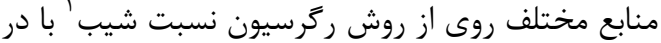

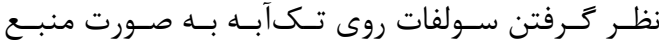

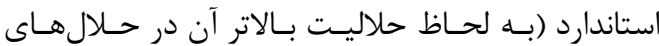

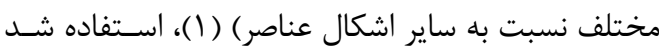

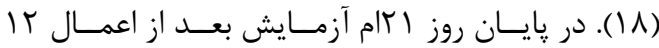

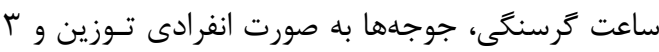

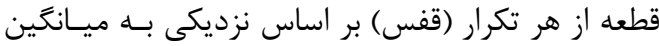

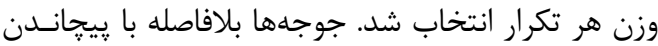

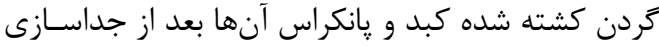

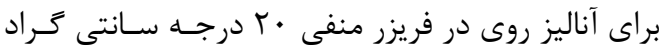

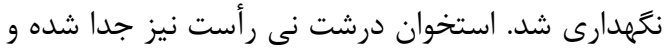

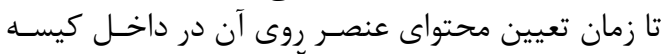

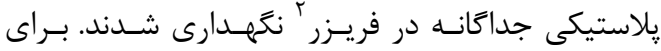

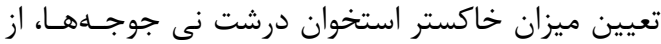

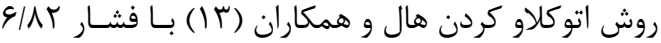

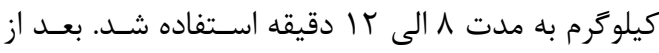

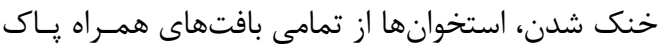

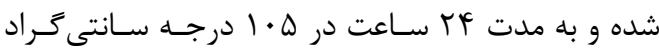

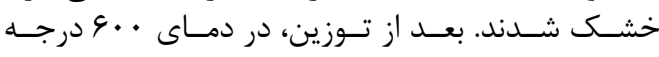

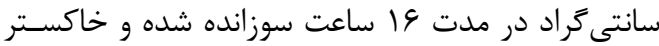

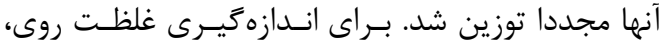

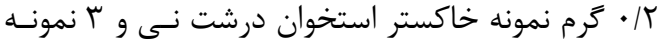

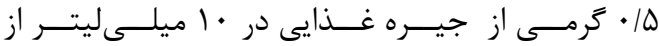

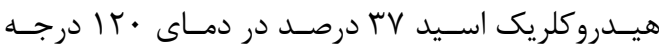

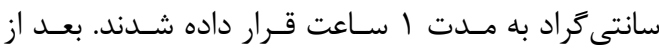

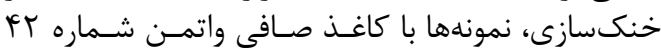

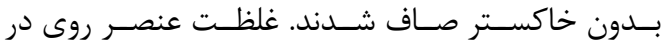

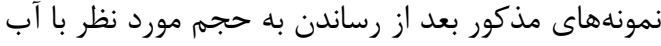

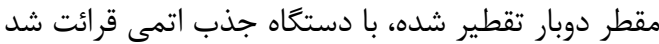

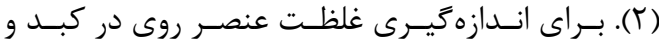

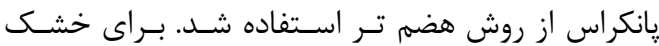

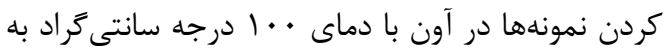


جدول r- تركيبات شيميايى منابع مختلف عنصر روى مورد مطالعه آناليز شده (به صورت As fed)

\begin{tabular}{|c|c|c|c|c|c|c|c|c|c|}
\hline منَكنز & آهن & مس & فسفر & كلسيم & روى & خشك ماده & ظاهرى & فرمول شيميايى & تركيبات" \\
\hline.$/ 94$ & $\Delta \cdot / F^{\alpha}$ &.$/ 14$ &.$/ \cdot 1$ & $T / \| \cdot \Delta$ & Tr & $9 / / \Delta$ & سفيد & $\mathrm{ZnSO}_{4} \cdot \mathrm{H}_{2} \mathrm{O}$ & سولفات روى \\
\hline $1 / \pi$ & $\Delta Q / T T$ & $r / l F$ & $\cdot / \cdot r$ & $r / 4 \lambda$ & $V \Delta$ & $99 / \mathrm{V}$ & سفيد & $\mathrm{ZnO}$ & A اكسيدروى A \\
\hline$\cdot / \mathrm{VI}$ & $11 \% / 8$ & $r / \cdot v$ & $\cdot / \cdot v V$ & T/FY & $V r$ & $1 \ldots$ & سفيد & $\mathrm{ZnO}$ & B اكسيدروى \\
\hline 1/ar & $V / r q$ & $\cdot \mid \Delta r$ & $.1 .1 \mathrm{~V}$ & $1 / 19$ & 10 & $9 \cdot 11$ & زرد & Bioplex Zn & بيويلكس روى ‘" \\
\hline
\end{tabular}

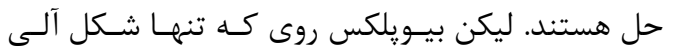

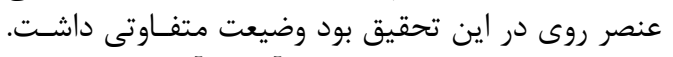

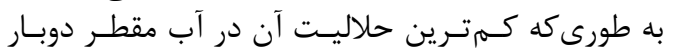

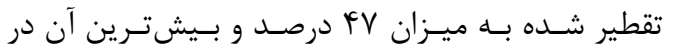

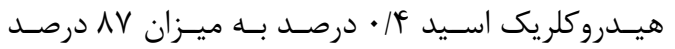
حاصل شد.
مطابق جدول ب سولفات روى تكىآبـه در آب مقطـر

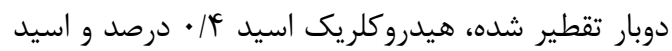

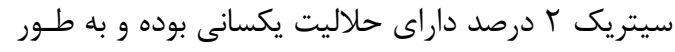

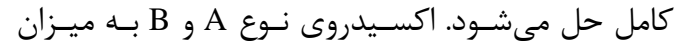

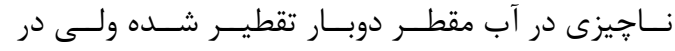

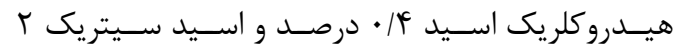

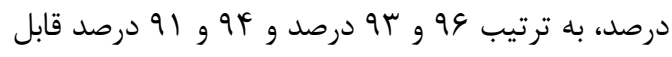

جدول ب- ارزيابى حلاليت منابع مختلف عنصر روى در حلالهاى مختلف (درصد)

\begin{tabular}{|c|c|c|c|}
\hline اسيد سيتريك & اسيد هيدروكلريدريك & دوبار تقطير شده & حلال منبع \\
\hline $1 \cdots$ & $1 \ldots$ & $1 \ldots$ & سولفات روى \\
\hline q & 94 & $1 / T r$ & A اكسيدروى \\
\hline 91 & 94 & r & B اكسيدروى B \\
\hline 99 & $\wedge \vee$ & FV & بيويلكس روى" \\
\hline
\end{tabular}

مىرسد مصرف دزهاى يايين اين منابع در ساخت معاي

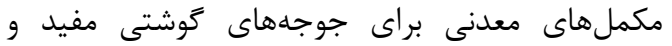
اقتصادى باشد.

بررسى ارزش زيستفراهمى منابع مختلف عند عنصر روى روى در جيرههاى نيمه خالص زيس

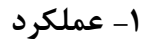

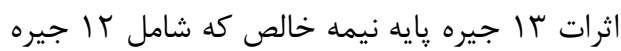

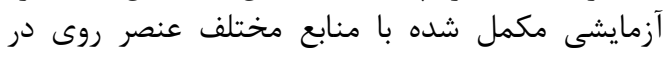

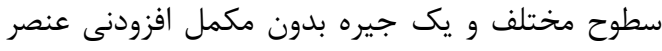

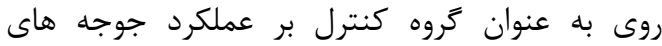

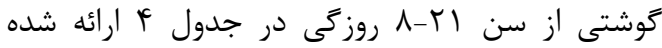

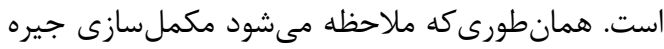

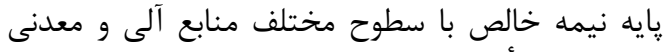

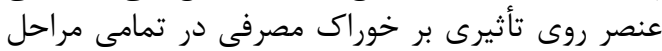

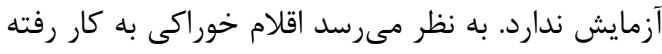

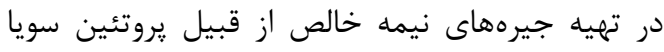

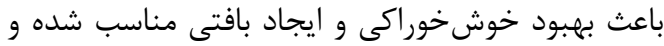

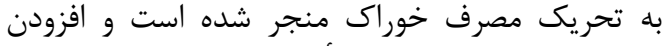

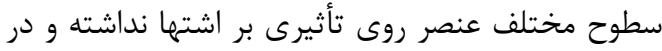

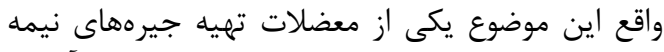

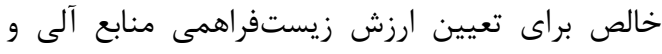

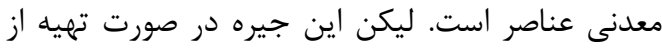

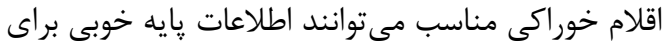

نتايج اين مطالعه اخرجه با نتايج ساير محققين

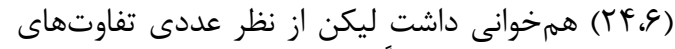

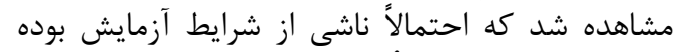

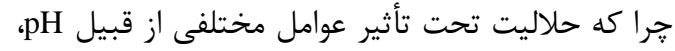

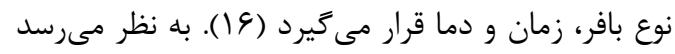

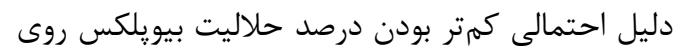

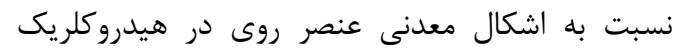

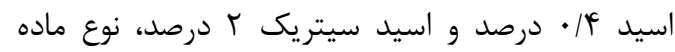

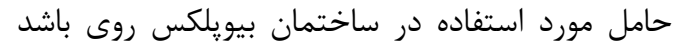
(IV)

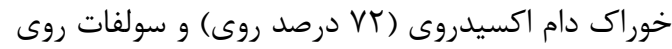

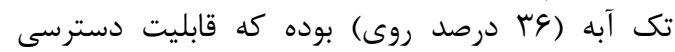

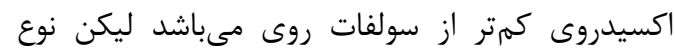

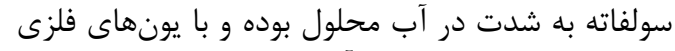

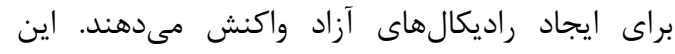

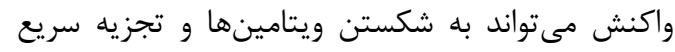

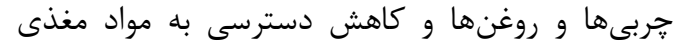

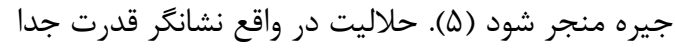

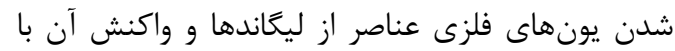

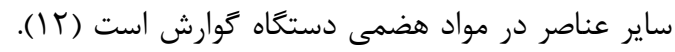

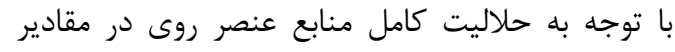

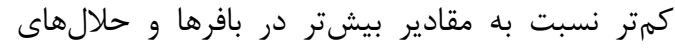

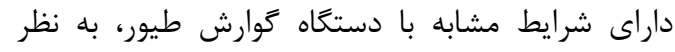




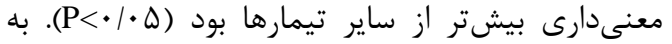

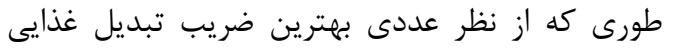

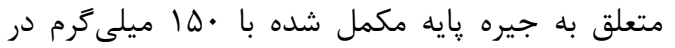

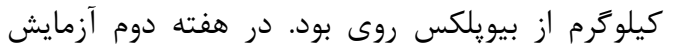

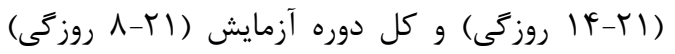

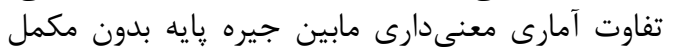

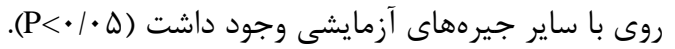

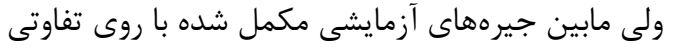

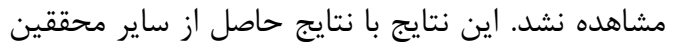

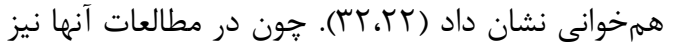

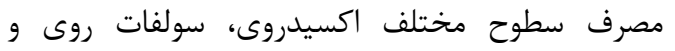

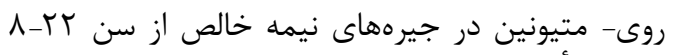
روزگى تأثيرى بر صفات عملكردى نداشت.
مقايسه ارزش بيوزيكى منابع آلى و معدنى عناصر در

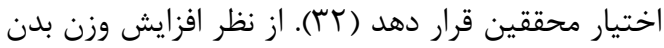

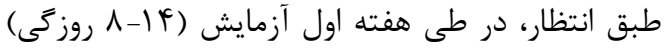

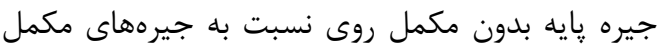

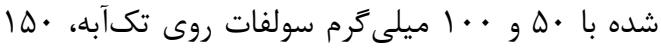
ميلى

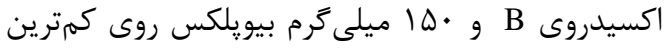

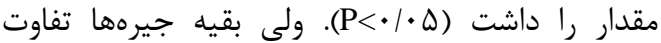

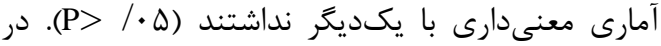

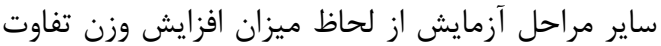

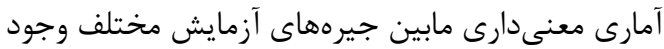

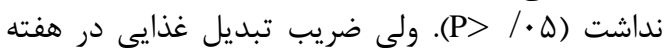

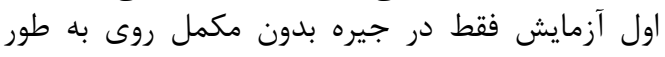

جدول ع- اثرات جيرههاى آزمايشى مختلف بر عملكرد جوجههاى كوشتى تغذيه شده با جيرههاى نيمه خالص از سن

\begin{tabular}{|c|c|c|c|c|c|c|c|c|c|}
\hline \multirow{2}{*}{\multicolumn{3}{|c|}{ ضريب تبديل غذايى (كرم: كرم) }} & \multirow{2}{*}{\multicolumn{3}{|c|}{ افزايش وزن بدن (كرم) }} & \multicolumn{4}{|c|}{ 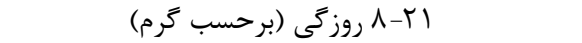 } \\
\hline & & & & & & & (5) & 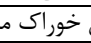 & صفات جيرههاى : \\
\hline$\lambda-r)$ & $|\Delta-r|$ & $\Lambda-14$ & A-YI & $|Q-r|$ & $1-14$ & $\langle-\Gamma|$ & $|Q-r|$ & $1-1 f^{2}$ & آزمايشىى \\
\hline$r / r^{a}$ & $r / \cdot \Delta^{a}$ & $T / \mathcal{E V}^{\mathrm{a}}$ & TQF & $190 / \cdots$ & $19 / .^{\circ}$ & $\Delta \Delta \Lambda$ & rTA/V. & $r / 9 / \Delta$. & جيره بايه (صفر) \\
\hline $1 / \Lambda 1^{0}$ & $1 / v r^{D}$ & $1 / 9 \Delta^{\circ}$ & ris & $195 / 10$ & $\mid r \Delta / \Lambda \cdot{ }^{a}$ & $\Delta V V / q$. & rrr/s. & rFY/Q. & سولفات روى •م \\
\hline$|/ \Lambda|^{0}$ & $\mid / N 1^{0}$ & $1 / 90^{\circ}$ & זQA/ז & IVNIIA & $\mid r \cdot 1 .^{a}$ & $\Delta f \cdot / \Delta$. & $r \cdot \Delta$ & rTr/a. & سولفات روى ... \\
\hline $1 / v \varphi^{\mathrm{D}}$ & $1 / 99^{\circ}$ & $1 / 9 \Upsilon^{\mathrm{b}}$ & $r \cdot N \leqslant \Delta$ & $190 / r$. & $\| r / r a^{a b}$ & $\Delta F I / F$. & TrYT/T. & $r / 9 / 1$. & سولفات روى .10 \\
\hline $1 / / \AA^{\circ}$ & $1 / V \Delta^{D}$ & $r / \varphi^{D}$ & rAV & $1 V \cdot / 90$ & $119^{\text {ab }}$ & $\Delta r V / \Delta$. & $r \cdots / 4$. & $r t r / 1$. & اكسيدروى A. A \\
\hline $1 / \Lambda 1^{0}$ & $1 / 44^{\circ}$ & $r / 9^{\circ}$ & гам/q. & $1 N N / 1 \Delta$ & $11 \cdot / v \Delta^{a b}$ & DFT/V. & $\mu 1 . / 0$. & rTT/T. & اكسيدروى A ..1 \\
\hline $1 / N v^{0}$ & $1 / 44^{0}$ & $1 / 9 \lambda^{0}$ & rIq/VQ & 19//9. & $\mid r \cdot / \Lambda \cdot \cdot^{a}$ & $\Delta 9 \Delta / r$. & rTGIV. & TrN/9. & 10 اكسيدروى A \\
\hline $1 / 1 / 9^{\circ}$ & $1 / 90^{\circ}$ & $r / 1^{\mathrm{D}}$ & rq4/TS & IVQ/VQ & $\| F / \Delta \cdot{ }^{a b}$ & DTA & rQN/D. & $r+q / \Delta$. & اكسيدروى B D. \\
\hline $1 / 19^{\circ}$ & $1 / v f^{0}$ & $r / 10^{\circ}$ & $r \wedge 9 / \Delta$. & I VV/VA & $|r| / v \cdot^{a}$ & DVF & $r q 1 / \Delta$. & $r \Delta \Delta / \Delta$. & اكسيدروى B .. 1 \\
\hline $1 / N \Lambda^{0}$ & $1 / 90^{\circ}$ & $r^{0}$ & TIT/TS & 19T/VQ & $\| N / \Delta \cdot \cdot^{a}$ & $\Delta \Delta V$ & rTI/D.. & TrG/V. & 10. B اكسيدروى \\
\hline $1 / A f^{\circ}$ & $1 / v^{0}$ & $r / 9^{\circ}$ & TQN/TV & $\mid A V / 9 D$ & $1.9 / 5 .{ }^{\text {ab }}$ & DFV & $r / 9 / \Delta$. & TTAIT. & بيويلكس روى •ه \\
\hline $1 / \Lambda \Delta^{\mathrm{D}}$ & $1 / 9 \Lambda^{\circ}$ & $r / / f^{D}$ & raN/TS & $\mid \Lambda r / \Delta \Delta$ & $\| F / V r^{a b}$ & $\Delta \Delta 1$ & $r .9 / 0$. & $r F \Delta / r$. & بيويلكس روى .. \\
\hline $1 / 1 / \varphi^{0}$ & $1 / v^{0}$ & $1 / A V^{D}$ & rIF/TD & IAV/AD & $|r g| k \cdot{ }^{a}$ & $\Delta \Delta F$ & $r r \cdot V$. & r r A & بيويلكس روى .10 \\
\hline 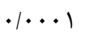 &.$\cdots 1$ & $\cdot \cdots r$ & $\cdot / 11 \Delta$ & $\cdot / \pi / 9$ &.$/ .10$ &.$/ 91$. & . /va. & $\cdot / 4 \lambda$ & P - value \\
\hline .1 .49 & $.1 .4 \lambda$ & $\cdot / \cdot v$ & $|r / 4|$ & $9 / r)$ & 91.0 & TF/TA & $I V / \Delta \Lambda$ & $1 . / 1 \mathrm{~V}$ & SEM $^{*}$ \\
\hline
\end{tabular}

ميانكَينهاى داراى حداقل يك حرف متفاوت در هر ستون اختلاف آمارى معنى دارى در سطح احتمال ه درصد با همديخر دارند.

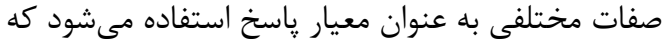

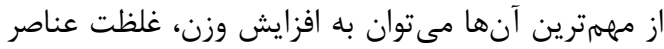

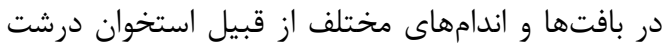

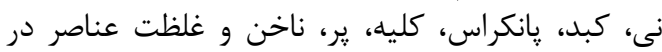

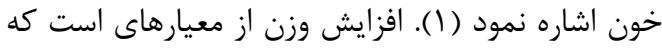

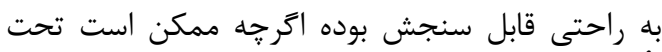

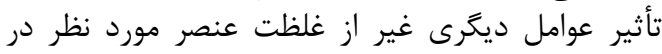

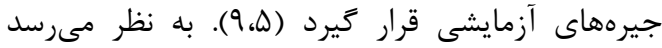

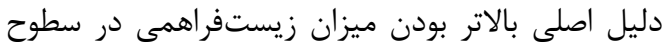

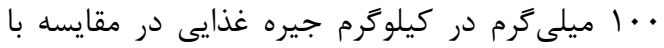

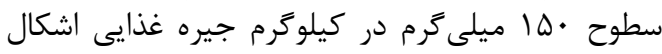

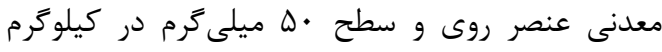

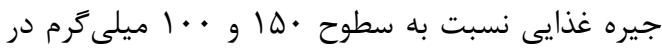

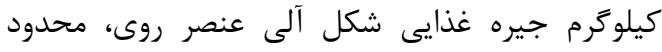

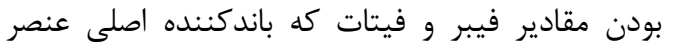

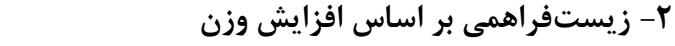

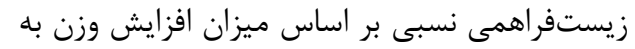

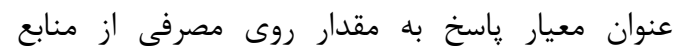

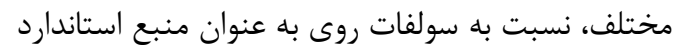

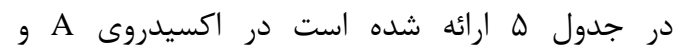

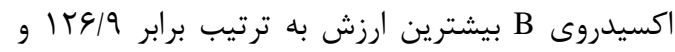

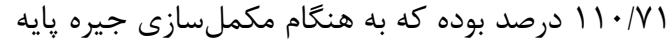

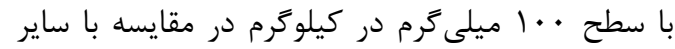

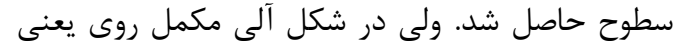

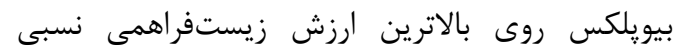

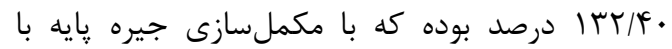

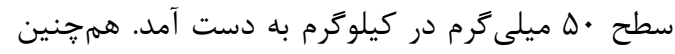

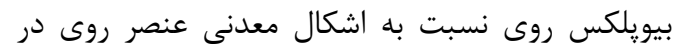

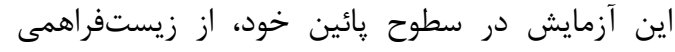
بالاترى برخوردار بود. براى تخمين زيستفراهمى ازئ آزين 
تغييرات ايجاد شده در متغير وابسته از طريق مدل قابل

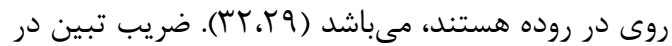

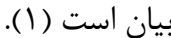

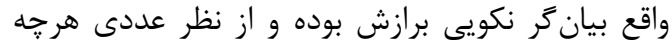
قدر ميزان آن بيشتر بكيى برازش، نشانكر آن است كه بيشتر

جدول هـ- تخمين زيستفراهمى نسبى منابع مختلف عنصر روى در جوجهائهاى كوشتى تغذيه شده با جيرههاى نيمه خالص

\begin{tabular}{|c|c|c|c|c|}
\hline تبيين (R2) & ازرش زيست فراهمى نسبى (RBV) & معادله ركر سيون" & 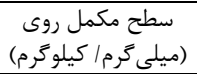 & منابع روى \\
\hline $91 / 9$ & $1 \cdots$ & $\mathrm{Y}=88.4+10.8 \mathrm{X}$ & $\Delta \cdot$ & \\
\hline$\$ 4 / 9$ & $1 \cdots$ & $\mathrm{Y}=180+4.20 \mathrm{X}$ & $1 \cdots$ & 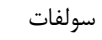 \\
\hline$V T / 4$ & $1 \cdots$ & $\mathrm{Y}=-48+9.88 \mathrm{X}$ & 10. & \\
\hline $9 \mathrm{~V} / 9$ & TV/T & $Y=160+4.01 \mathrm{X}$ & $\Delta \cdot$ & \\
\hline $9 \$ / 0$ & $1 \% \varepsilon / 9$. & $\mathrm{Y}=34.3+5.33 \mathrm{X}$ & $1 \cdots$ & A اكسيد A \\
\hline$v \cdot / 1$ & $F \Psi / V K$ & $Y=-2+4.42 X$ & 10. & \\
\hline$\Delta 1 / 9$ & $r F / q$. & $\mathrm{Y}=189+3.77 \mathrm{X}$ & $\Delta \cdot$ & \\
\hline$v \Delta / 1$ & $11 \cdot / 21$ & $Y=47.3+4.65 X$ & $1 \ldots$ & اكسيد B \\
\hline $9 \Delta / 9$ & $\Delta \Delta / 9 V$ & $\mathrm{Y}=-79.5+5.53 \mathrm{X}$ & 10. & \\
\hline$\Delta \mathrm{V} / \mathrm{T}$ & $\mid r r / 4$. & $\mathrm{Y}=117+14.3 \mathrm{X}$ & $\Delta \cdot$ & \\
\hline $9 \cdot / r$ & $1 \cdot \varphi / v e$ & $\mathrm{Y}=220+4.4 \mathrm{X}$ & $1 \ldots$ & بيويلكس ب بي \\
\hline$V g / 4$ & ITT/FE & $\mathrm{Y}=98.2+12.1 \mathrm{X}$ & 10 . & \\
\hline
\end{tabular}

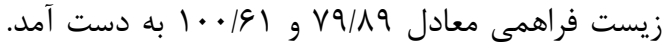

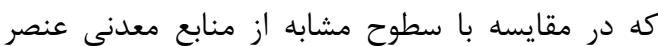

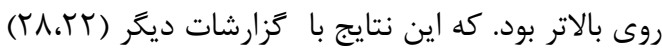

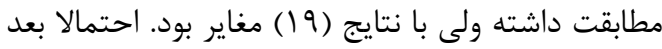

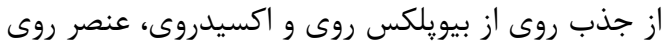

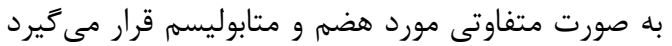

زيستفراهمى نسبى تخمين زده شده در خر خصوص

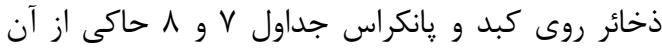

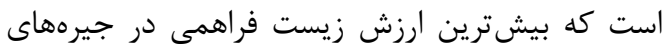

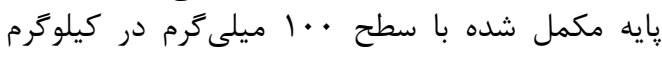

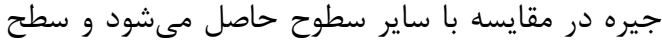

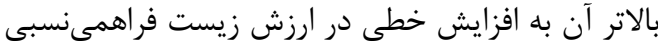

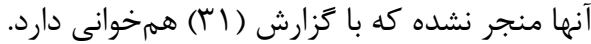

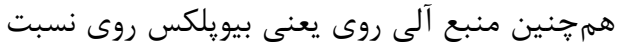

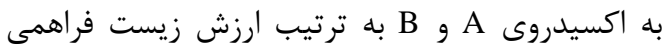

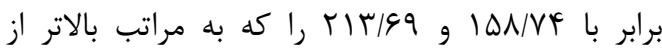

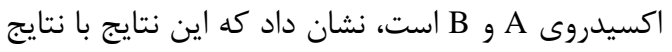

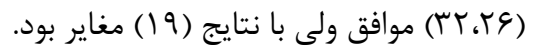

ץ- زيستفراهمى بر اساس غلظت روى در استخوان

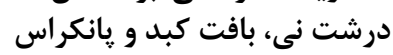

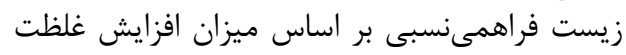

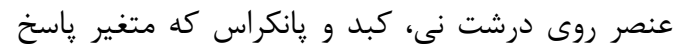

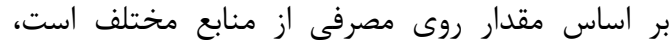

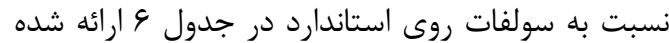

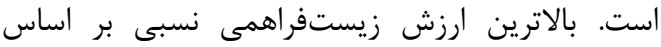

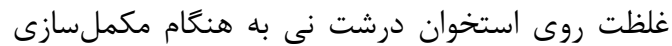

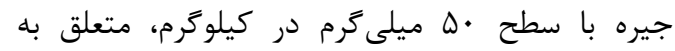

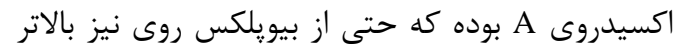

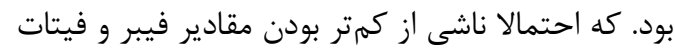

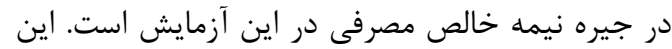

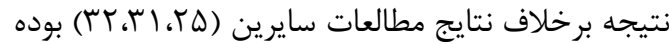

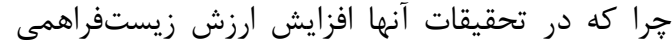

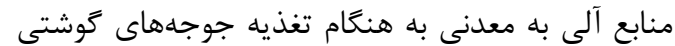

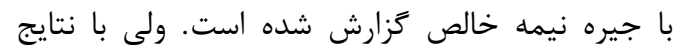

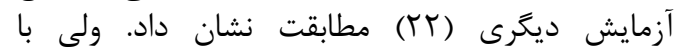

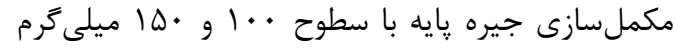
در كيلوكرم جيره از بيويلكس روى بائ به ترتيب ارزش 

تخمين زيستفراهمى منابع مختلف عنصر روى در جوجههاى گوشتى تغذيه شده با جيرهاى نيمه خالص .

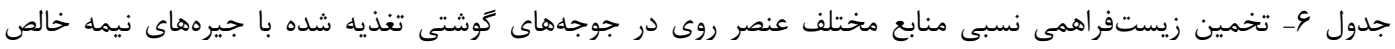

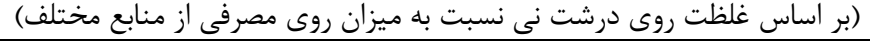

\begin{tabular}{|c|c|c|c|c|}
\hline تبيين (R2) & ازرش زيست فراهمى نسبى (RBV) & * ركرسيون & (ميلى كرم/ مكلول رومى) & منابع روى \\
\hline $9 \Delta / 4$ & $1 \cdots$ & $\mathrm{Y}=117+13.3 \mathrm{X}$ & $\Delta \cdot$ & \\
\hline $91 / 9$ & $1 \ldots$ & $\mathrm{Y}=43.3+18.4 \mathrm{X}$ & $1 \cdots$ & سولفات \\
\hline $9 / / 4$ & $1 \ldots$ & $\mathrm{Y}=74.1+16 . .2 \mathrm{X}$ & 10. & \\
\hline$\Lambda V / r$ & $\Lambda \cdot / f \Delta$ & $\mathrm{Y}=166+10.7 \mathrm{X}$ & $\Delta \cdot$ & \\
\hline$\Lambda 9 / \Gamma$ & rs & $Y=212+6.63 X$ & $1 \ldots$ & A اكسيد A \\
\hline$\Lambda \Delta / r$ & $r \Delta / \Delta \omega$ & $\mathrm{Y}=19+5.76 \mathrm{X}$ & 10. & \\
\hline $91 / 4$ & rq/vV & $\mathrm{Y}=212+5.29 \mathrm{X}$ & $\Delta \cdot$ & \\
\hline$V T / r$ & rV/A & $\mathrm{Y}=158+6.97 \mathrm{X}$ & $1 \cdots$ & اكسيد B \\
\hline$v \cdot / 4$ & re/IV & $\mathrm{Y}=199+5.86 \mathrm{X}$ & 10. & \\
\hline$\Lambda T / \Lambda$ & TN/FT & $\mathrm{Y}=399+5.11 \mathrm{X}$ & $\Delta \cdot$ & \\
\hline $9 / / r$ & $\vee १ / \wedge 9$ & $\mathrm{Y}=13.8+14.7 \mathrm{X}$ & $1 \cdots$ & بيويلكس \\
\hline 9911 & $1 \cdots|9|$ & $Y=339+16.3 X$ & 10 . & \\
\hline \multirow{2}{*}{\multicolumn{5}{|c|}{ 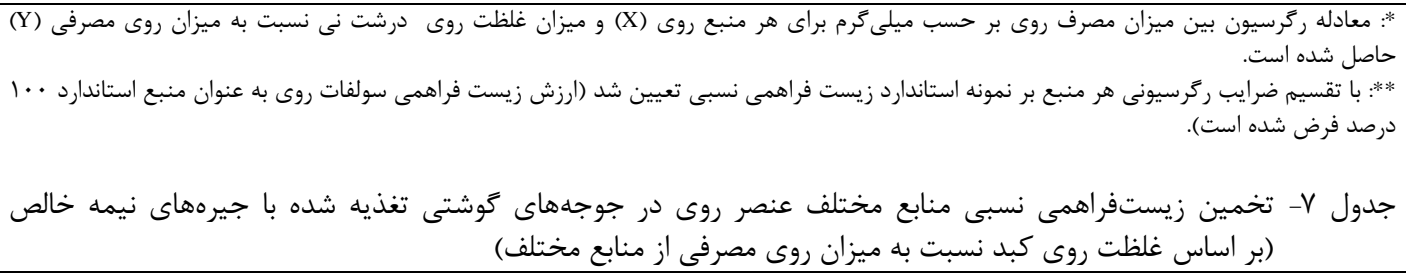 }} \\
\hline & & & & \\
\hline $\begin{array}{c}\text { ضريب } \\
\text { (R2) } \\
\text { (R2) }\end{array}$ & $\begin{array}{l}\text { ازرش زيست فراهمى نسبى (/.) (RBV) } \\
\text { (.) }\end{array}$ & ر ركرسيون * معادله & 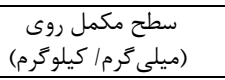 & منابع روى \\
\hline $99 / 1$ & $1 \cdots$ & $\mathrm{Y}=5.4+8.14 \mathrm{X}$ & $\Delta$ & \\
\hline$\Lambda \omega / 9$ & $1 \cdots$ & $\mathrm{Y}=35.5+5.08 \mathrm{X}$ & 1. & سولفات \\
\hline$\Lambda V / \Delta$ & 1. & $\mathrm{Y}=10.2+5.28 \mathrm{X}$ & 10. & \\
\hline $9 \cdot 19$ & $99 / 01$ & $Y=43.5+5.42 X$ & $\Delta \cdot$ & \\
\hline$q \Delta / r$ & $1.9 / F F$ & $\mathrm{Y}=1.5+4.56 \mathrm{X}$ & $1 \cdots$ & A اكسيد \\
\hline $9 \wedge / \Delta$ & rV/GV & $\mathrm{Y}=27.4+1.99 \mathrm{X}$ & 10 . & \\
\hline $9 \vee / \Delta$ & re/vr & $\mathrm{Y}=21.3+2.99 \mathrm{X}$ & $\Delta \cdot$ & \\
\hline $9 V / 9$ & $f Q / F V$ & $\mathrm{Y}=99.7+2.31 \mathrm{X}$ & $1 \ldots$ & اكسيد B \\
\hline $11 / 1$ & $r \Delta / \Delta \varphi$ & $\mathrm{Y}=165+1.35 \mathrm{X}$ & 10. & \\
\hline$q q / 4$ & fe/ar & $\mathrm{Y}=131+3.82 \mathrm{X}$ & $\Delta \cdot$ & \\
\hline$\vee १ / q$ & $\mid \Delta N / V F$ & $\mathrm{Y}=75.7+7.95 \mathrm{X}$ & $1 \ldots$ & بيويلكس \\
\hline$\Lambda V / G$ & $|\mp V / q|$ & $\mathrm{Y}=103+7.81 \mathrm{X}$ & 10 & \\
\hline \multirow{2}{*}{\multicolumn{5}{|c|}{ 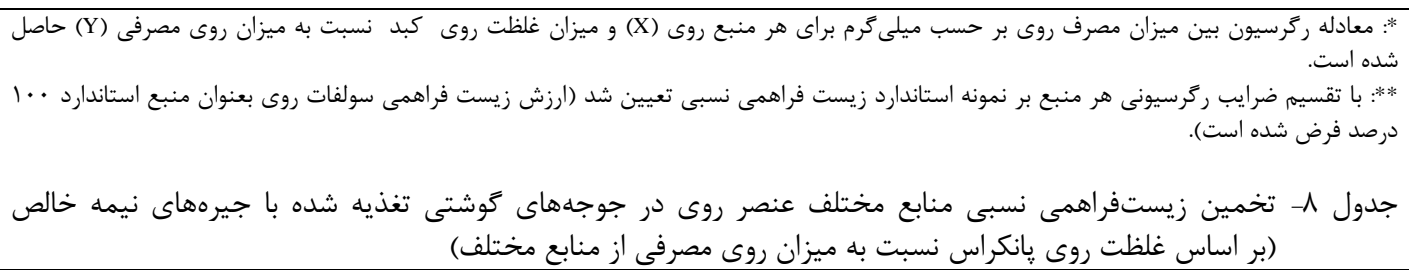 }} \\
\hline & & & & \\
\hline $\begin{array}{c}\text { ضريب (R2) } \\
\text { (R2) }\end{array}$ & ازرش زيست فراهمى نسبى & معادله ركرسيون* & ميلى كرم/ كيلوكر روم) & منابع روى \\
\hline $94 / V$ & $1 \cdots$ & $\mathrm{Y}=5.5+6.46 \mathrm{X}$ & $\Delta \cdot$ & \\
\hline $9 \pi / T$ & $1 \cdots$ & $\mathrm{Y}=42.1+4.82 \mathrm{X}$ & $1 \cdots$ & سولفات \\
\hline $94 / 9$ & 1. & $Y=76.7+7.44 X$ & 10. & \\
\hline ar & $\Delta 1 / T r$ & $\mathrm{Y}=48.7+3.31 \mathrm{X}$ & $\Delta \cdot$ & \\
\hline$V T / 9$ & $\Lambda q|\Delta|$ & $\mathrm{Y}=60+4.17 \mathrm{X}$ & $1 \ldots$ & A اكسيد \\
\hline $9 \Delta / r$ & $r \cdot / v V$ & $\mathrm{Y}=11.4+2.29 \mathrm{X}$ & 10 . & \\
\hline$\Lambda \kappa / 9$ & $99 / \Gamma \wedge$ & $\mathrm{Y}=18.3+6.22 \mathrm{X}$ & $\Delta \cdot$ & \\
\hline १९ & $\Lambda T / \Lambda Q$ & $\mathrm{Y}=10.4+3.96 \mathrm{X}$ & $1 \cdots$ & اكسيد B \\
\hline $99 / 5$ & $r 9|9|$ & $\mathrm{Y}=118+1.98 \mathrm{X}$ & 10. & \\
\hline$V V / 9$ & Ifa & $\mathrm{Y}=88.5+6.99 \mathrm{X}$ & $\Delta \cdot$ & \\
\hline $9 V /\left.\right|^{\leftarrow}$ & rIr/9q & $\mathrm{Y}=69.8+10.3 \mathrm{X}$ & $1 \ldots$ & بيويلكس \\
\hline $9 Y / \Lambda$ & $1 r 9 / v \wedge$ & $\mathrm{Y}=46.6+10.4 \mathrm{X}$ & 10. & \\
\hline
\end{tabular}




$$
\Delta V
$$$$
\text { سطح • ه ميلى گرم در كيلوگرم جيره پايه حاصل شد. }
$$

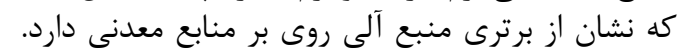

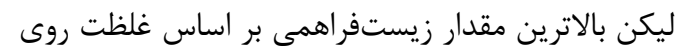

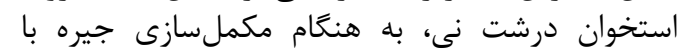

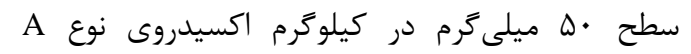$$
\text { مشاهده شد. }
$$

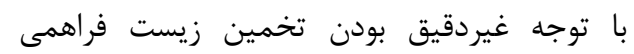

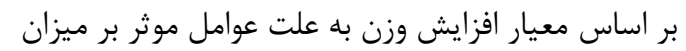

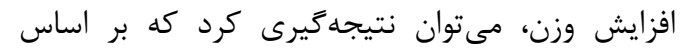

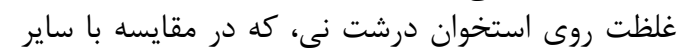

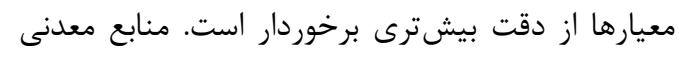

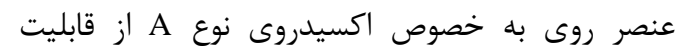

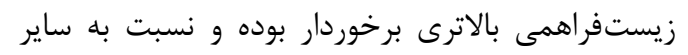$$
\text { منابع مورد مطالعه ارجحيت دارد. }
$$

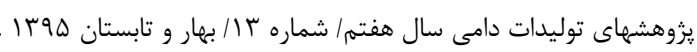

$$
\begin{aligned}
& \text { در مطالعهاى (YN) با مكملسازى جيره يايه حاوى }
\end{aligned}
$$

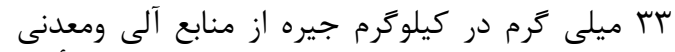

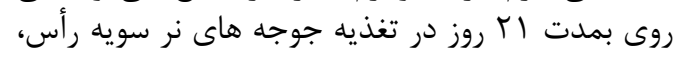

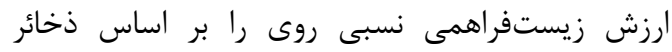

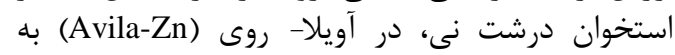

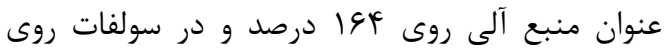

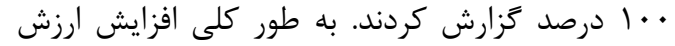

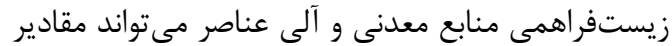

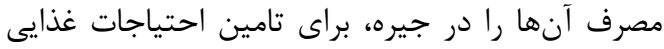

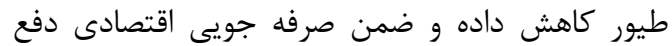

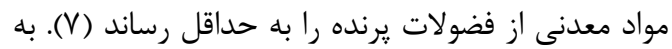

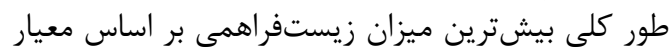

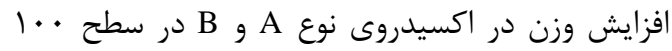

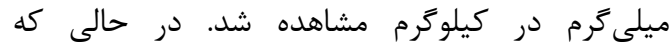

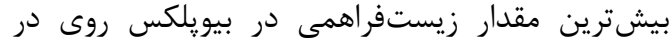

1. Ammerman, C.B. D.H. Baker and A.J. Lewis. 1995. Bioavailability of Nutrients for Animals: Amino Acids, Minerals and Vitamins. Academic Press, San Diego, CA.

2. AOAC. 1995. Official Methods of Analysis, 16th ed. Association of Official Analytical Chemists, Arlington, VA.

3. Aviagen. 2007. Ross Broiler Management Guide.

4. Bao, Y.M. and M. Choct. 2009. Trace mineral nutrition for broiler chickens and prospects of application of organically complexes trace minerals: a review. Animal Production Science, 49: 269282.

5. Batal, A.B., T.M. Parr and D.H. Baker. 2001. Zinc Bioavailability in tetrabasic zinc chloride and the dietary zinc requirement of young chicks fed soy concentrate diet. Poultry Science, 80: 87-90

6. Cao, J., P.R. Henry, R. Guo, R.A. Holwerda, J.P. Toth, R.C. Littell, R.D. Miles and C.B. Ammerman. 2000. Chemical characteristics and relative bioavailability of supplemental organic zinc sources for poultry and ruminants. Journal of Animal Science, 78: 2039-2054.

7. Cheng J., E.T. Kornegay and T. Schell. 1998. Influence of dietary lysine on the utilization of zinc from zinc sulfate and a zinc lysine complex by young pigs. Journal of Animal Science, 76: 1064-1074.

8. Dewar, W.A. and J.N. Downie. 1984. The zinc requirements of broiler chicks and turkey poults fed on purified diets. British Journal of Nutrition, 51: 467-477.

9. Emmert, J.L. and D.H. Baker. 1995. Zinc stores in chickens delay the onset of zinc deficiency symptoms. Poultry Science, 74: 1011-1021.

10. Etcheverry, P., A. Michael and L.E. Fleige. 2012. Application of invitro bioaccessibility and bioavailability methods for calcium, carotenoids, folate, iron, magnesium, polyphenols, zinc and vitamins B6, B12, D and E, Volume 3 Article 317.

11. INRA. 1989. L. alimentationdes animaux monogastriques: porc, lapin, volailles, 2. Ed. Pari

12. Guo, R., P.R. Henry, R.A. Holwerda, J. Cao, R.C. Littell, R.D. Miles and C.B. Ammerman. 2001. Chemical characteristics and relative bioavailability of supplemental organic copper sources for poultry. Journal Animal Science, 79: 1132-1141.

13. Hall, L.E., R.B. Shirley, R.I. Bakalli, S.E. Aggrey, G.M. Pesti and Jr H.M. Edwards. 2003. Power of two methods for the estimation of bone ash of broilers. Poultry Science, 82: 414-418.

14. Huang, Y.L., L. Lu, X.G. Luo and B. Liu.2007. An optimal dietary zinc level of broiler chicks fed a corn-soybean meal diet, Poultry Science, 86: 2582-2589.

15. Leeson, S. 2003. A new look at the trace mineral nutrition of poultry: Can we reduced environmental burden of poultry manure? In Nutritional Biotechnology in the Feed and Food Industries. T.P. Lyons and K.A. Jacques, ed. Nottingham University Press, Nottingham, UK. 125-131.

16. Leach, G.A. and R.S. Patton. 1997. Analysis techniques for chelated minerals evaluated. Feedstuffs 69:13-15.

17. Li, S.F., X. Luo, B. Liu, T.D. Crenshaw, X. Kuang and G. Shao. 2004. Use of chemical characteristics to predict relative bioavailability of supplemental organic manganese sources for broilers. Journal Animal Science, 82: 2352-2363.

18. Littell, R.C., P.R. Henry, A.J. Lewis and C.B. Ammerman. 1997. Estimate of relative bioavailability of nutrients using SAS procedures. Journal of Animal Science, 75: 2672-2683

19. NRC. 1994. Nutrient Requirements of Poultry, 9th ed. Natl. Acad. Press, Washington, DC.

20. Park, S.Y., S.G. Birkhold, L.F. Kubena, D.J. Nisbet and S.C. Ricke. 2004. Review on the role of dietary zinc in poultry nutrition, immunity and reproduction. Biological Trace Element Research, 101(2): 147-163.

21. Perkin Elmer Corporation. 1982. Analytical Methods for Atomic Absorption Spectrophotometry, Norwalk, CT. 


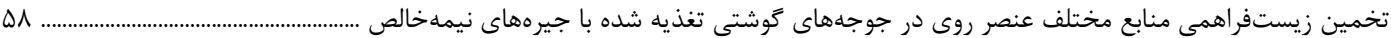

22. Pimentel, J.L., M.E. Cook and J.L. Greger. 1991. Research note bioavailability of zinc-methionine for chicks. Poultry Science, 70: 1637-1639.

23. SAS. 1999. SAS User's Guide: Statistics. Version 9.1 ed. SAS Inst. Inc., Cary, NC.

24. Sandoval, M., P.R. Henry, C.B. Ammerman, R.D. Miles and R.C. Littell. 1997. Relative bioavailability of supplemental inorganic zinc sources for chicks. Journal of Animal Science, 75: 3195-3205.

25. Sandoval, M., P.R. Henry, X.G. Luo, R.C. Littell, R.D. Miles and C.B. Ammerman. 1998. Performance and tissue zinc and metallothionein accumulation in chicks fed a high dietary level of zinc. Poultry Science, 77: 1354-1363.

26. Schlege, P., D. Sauvant and C. Jondreville. 2013. Bioavailability of zinc sources and their interaction with phytates in broilers and piglets. Animal, 7: 47-59

27. Spears, J.W. 1989. Zinc Methionine for ruminants: Relative bioavailabilityof zinc in lambs and effects of growth and performance of growing heifers. Journal of Animal Science, 67: 835-843.

28. Star, L., J.D. Van der Klis, C. Rapp and T.L. Ward. 2012. Bioavailability of organic and inorganic zinc sources in male broilers. Poultry Science, 91: 3115-3120.

29. Suttle, N.F. 2010. Mineral Nutrition of Livestock, $4^{\text {th }}$ Edition CABI Head Office Nosworthy Way Wallingford. Oxfordshire, OX10 8DE. UK.

30. Watson, L.T., C.B. Ammerman, S.M. Miller and R.H. Harms. 1970. Biological assay of inorganic manganese for chicks. Poultry Science, 49: 1548-1554

31.Wedekind, K.J. and D.H. Baker. 1990. Zinc bioavailability in feed-grade sources of zinc. Journal of Animal Science, 68: 684-689.

32. Wedekind, K.J., A.E. Hortin and D.H. Baker. 1992. Methodology for assessing zinc bioavailability: Efficacy estimates for zinc methionine, zinc sulfate and zinc oxide. Journal of Animal Science, 70: 178-187. 


\title{
Estimation of the Relative Bioavailability of Different Zinc Sources in Broiler Chickens Fed by Semi-Puirfeid Diets
}

\author{
Mahmood Sahraei ${ }^{1}$ and Hossein Janmohammadi ${ }^{2}$ \\ 1- Animal Science Research Department, Ardabil Agricultural and Natural Resources Research and \\ Education Center, AREEO, Ardabil, Iran (Corresponding author: m.sahraei2009@gmail.com) \\ 2- Associate Professor, University of Tabriz \\ Accepted: January 2, $2014 \quad$ Received: July 7, 2014
}

\begin{abstract}
An experiment was conducted to estimate the bioavailability and evaluation chemical properties of different zinc sources such as zinc sulfate, zinc oxide A, zinc oxide B and Bioplex $\mathrm{Zn}$ in broiler chickens fed by semi-puirfeid diets., At first, for chemical and solubility evaluation of different zinc sources in different solvents based on standards methods, 3 samples each containing 1 and $0.1 \mathrm{~g}$, respectively, were used the results showed that zinc concentration is varied from $15 \%$ in Bioplex $\mathrm{Zn}$ to $75 \%$ in zinc oxide A. The highest solubility about $100 \%$ obtained in the double distilled water, $0.4 \% \mathrm{HCL}$ and $2 \%$ citric acid is related to zinc sulfate but the lowest solubility observed in the double distilled water, $0.4 \%$ hydrochloric acid and $2 \%$ citric acid is related to Bioplex $\mathrm{Zn}$. In the following, for study the bioavailability of different zinc sources, of a 13 semi-purified diets supplemented by 50,100 or $150 \mathrm{mg}$ of different zinc sources per $\mathrm{kg}$ of diet in feeding of 260 Ross-308 male broiler chickens in completely randomized design with 4 replicates and 6 birds per each in cage system from 8-21days of age were used. For estimation of relative bioavailability slope ratio method was used. In this method relative bioavailability of different zinc sources, calculated by dividing of regression equation coefficient to regression equation coefficient of zinc sulfate as a standard sources. The highest bioavailability value, based on weight gain, was obtained in diets supplemented by $100 \mathrm{mg}$ zinc oxide $\mathrm{A}$ and $\mathrm{B}$, but the highest bioavailability value for Bioplex $\mathrm{Zn}$ was found in $50 \mathrm{mg}$ zinc supplemented per $\mathrm{kg}$ of basal diet $(\mathrm{P}<0.05)$. The highest amount of zinc bioavailability based on tibia zinc concentration was obtained in $50 \mathrm{mg}$ zinc supplemented per $\mathrm{kg}$ of diet with zinc oxide A, but according to the zinc concentration in liver and pancreas, the highest value were seen in basal diet supplemented whit $100 \mathrm{mg}$ Bioplex $\mathrm{Zn}$ per $\mathrm{kg}$ of diets $(\mathrm{P}<0.05)$.
\end{abstract}

Keywords: Bioavailability, Broiler chicken, Semi-puirfeid diet, Solubility, Zinc 